\title{
Experimental Study on Seismic Attenuation and Permeability of Large Porosity Rock
}

\author{
Xiaochen Yang1* ${ }^{*}$ Kyuro Sasaki ${ }^{1}$, Xiaoming Zhang ${ }^{2}$, Yuichi Sugai ${ }^{1}$ \\ ${ }^{1}$ Department of Earth Resources Engineering, Kyushu University, Fukuoka, Japan \\ ${ }^{2}$ Institute of Engineering and Environment, Liaoning Technical University, Huludao, China \\ Email: `xiaochen2024123@gmail.com, krsasaki@mine.kyushu-u.ac.jp,xmzhang7@gmail.com, sugai@mine.kyushu-u.ac.jp
}

How to cite this paper: Yang, X.C., Sasaki, K., Zhang, X.M. and Sugai, Y.C. (2018) Experimental Study on Seismic Attenuation and Permeability of Large Porosity Rock. Journal of Geoscience and Environment Protection, 6, 80-90.

https://doi.org/10.4236/gep.2018.65007

Received: February 2, 2018

Accepted: May 20, 2018

Published: May 23, 2018

\begin{abstract}
The large porosity areas widely present in the underground resulting from natural hazards or artificial damages. The porosity and permeability are suggested to be capable of estimating the mechanical and air flow conditions inside the porous layer in the underground. To accurately measure the porosity and permeability in the porous area is imperative. To address this issue, we experimentally modeled some porous samples in large porosities by using sandstone particles sieved to different sizes. Ultrasonic was employed to apply on the porous sandstone samples to characterize the seismic velocity and attenuation. Permeability was also measured simultaneously to find a correlation with the porosity. The results showed the seismic attenuation decrease as the reduction of frequency and increasing particle size at the same porosity. Seismic attenuation was strongly correlated to porosity and particle size. Velocity showed a good relationship with the porosity change. Permeability was highly dependent on the particle size especially in the higher porosity range. The results indicated that it is possible to find a relationship between the permeability and seismic attenuation via the porosity and particle size.
\end{abstract}

\section{Keywords}

Porous Area, Ultrasonic Measurement, Seismic Attenuation, Porosity, Permeability

\section{Introduction}

The longwall mining method was widely applied in the underground coal mine since 1970s because of its higher production efficiency compared to room-and-pillar method [1]. Presently, it is mainly used in the big coal-production countries such as China, USA, Australia and Eastern Europe, especially in China. Around $90 \%$ of the coal is produced by underground mining operation in China [2], the 
majority of which conducted by longwall mining. However, the large-scale excavation lead to the serious strata deformation and damage resulting in a numerous bended, fractured and porous areas in the underground [3]. Because the porous areas contain a considerable high void ratio which could lead to the leakage of ventilation airflow from the underground to the surface [4]. Simultaneously, the methane from the adjacent coal seam is possible to flow into the working face causing a big threaten to the people and equipments [5]. Thus, the representation of the porous areas in the underground needs to be precisely provided. The porosity and permeability are the mainly parameters to characterize the porous areas [6]. However, to directly measure them in the porous areas is difficult because of the inaccessibility deep in the underground. Thus, the common approach for measurements are mainly consist of seismic method (3D seismic, Rayleigh wave method, vertical seismic profile), electromagnetic method, gravity method, radioactive method and gravity method and so on [7] [8]. The seismic method is the most common one because of its reliability and simplicity. At present, the key point of the seismic method is the variation of the velocity/attenuation of the reflected or refraction waves propagating through the object body. For the cases of the underground detection, some investigations have been carried out to assess the position and extent of the anomalies [9] [10]. For instance, USA Mine Safety and Health Administration has successfully predicted the position of the suspected fractured zones by cross-hole seismic method in the eastern United States [11]. With the knowledge that the porosity and permeability in the porous areas are significant for evaluating the stability of the porous areas and gas flow characterization.

Thus, in this study, we used the sandstone particles to make porous samples to study the wave and gas flow characterization in the porous material. The ultrasonic wave was employed to measure the velocity and attenuation of the transmitted wave propagating through the porous samples at different frequencies. The porosity, permeability and wave parameters of the porous samples were measured to find relationships between them.

\section{Methodology}

According to the research of Fumagalli [12], the grain size distribution of the actual rockfill materials could be proportionally scaled down and accurately represented for laboratory tests. Furthermore, Hardlin [13] provided theoretically that the strength and deformation characteristic of the $5 \mathrm{~cm}$ maximum particle size materials could be considered the same as those of the large fragments. Therefore, lab-scale sample consisting of the smaller particles but similar size distribution is capable of providing a similar mechanical condition of the actual scale in the field. In this study, we used three groups of sandstone particles with different size diameter whose distribution was shown in Figure 1.

It is known that the porosity of the porous layer in the field is approximately $20 \%-40 \%[14]$. We therefore kept the porosity of the porous samples used for 
measurement within this range. The porosity of the samples were controlled by a compressive loading and laser rangefinder. Meanwhile, the elastic modulus of the samples at the expected porosity were measured. Elastic modulus was measured under different porosity and particle size shown in Figure 2.

\section{Experimental Measurement}

\subsection{Ultrasonic Measurement}

Particles of sandstone were sieved into three groups by size. The range of size for

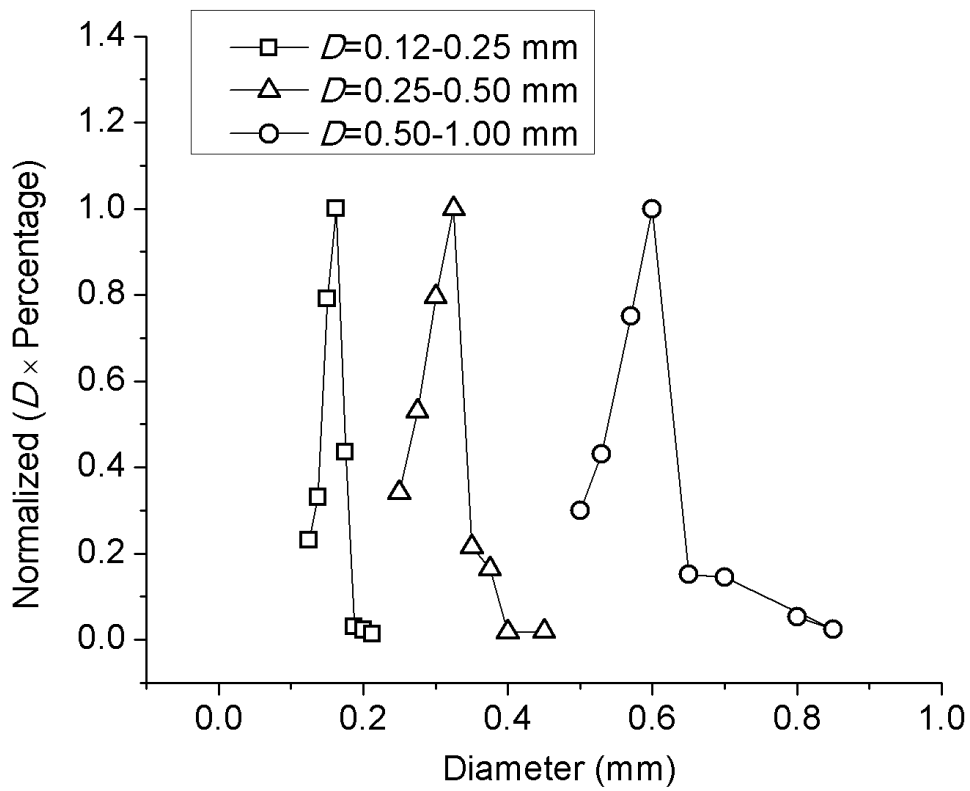

Figure 1. Size distribution of particles in laboratory measurement.

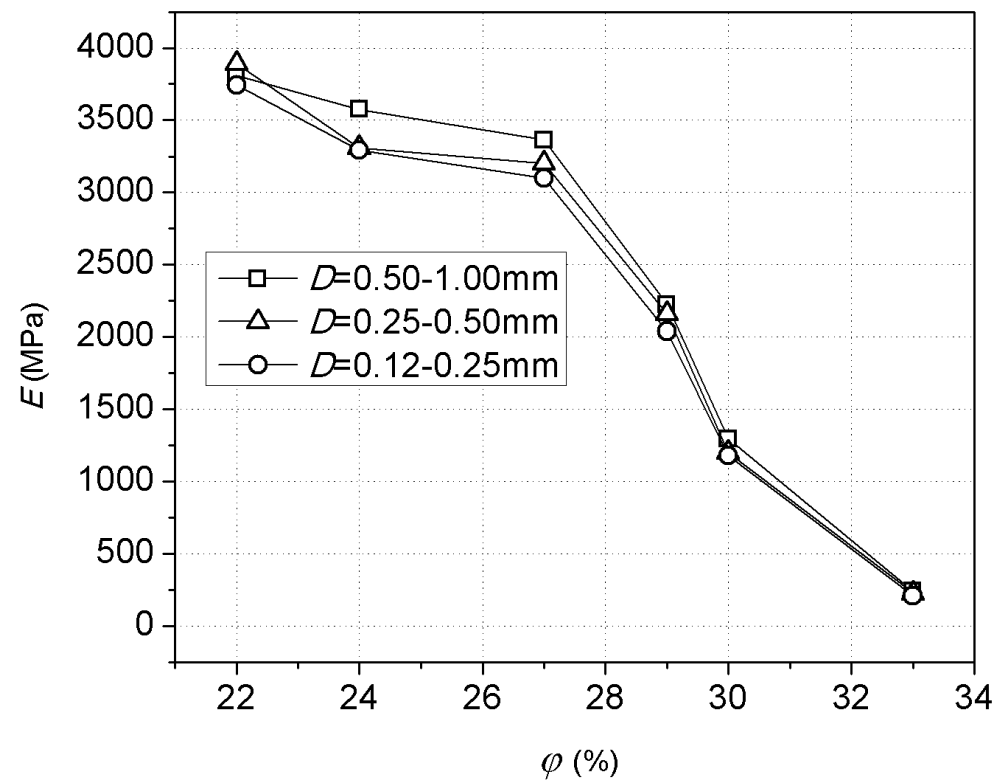

Figure 2. Elastic modulus changes with porosity for porous sandstone samples in different particle size. 
three groups are $D=0.12-0.25 \mathrm{~mm}, 0.25-0.50 \mathrm{~mm}$ and $0.50-1.00 \mathrm{~mm}$, respectively. The size of these particles were proportional scaled down to the actual mass distribution in the abandoned area. Subsequently, the particles were compressed into cylindrical PVC pipes $40 \mathrm{~mm}$ in internal diameter which were also surrounded by a stainless-steel socket. The cylindrical porous samples were compressed by a stainless-steel piston $39.8 \mathrm{~mm}$ in diameter through the PVC pipe under high compression using the press molding machine (Figure 3(a)). The porosity of the porous samples was controlled by compression force applied on the particles with stepwise loading in order to keep the homogeneity and
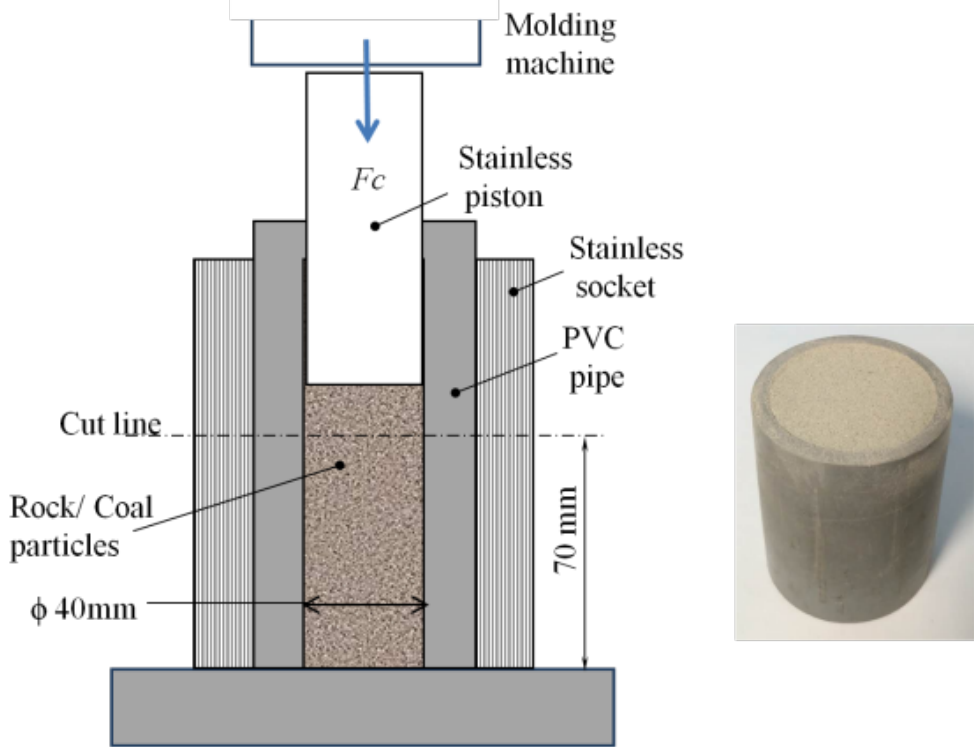

(a)

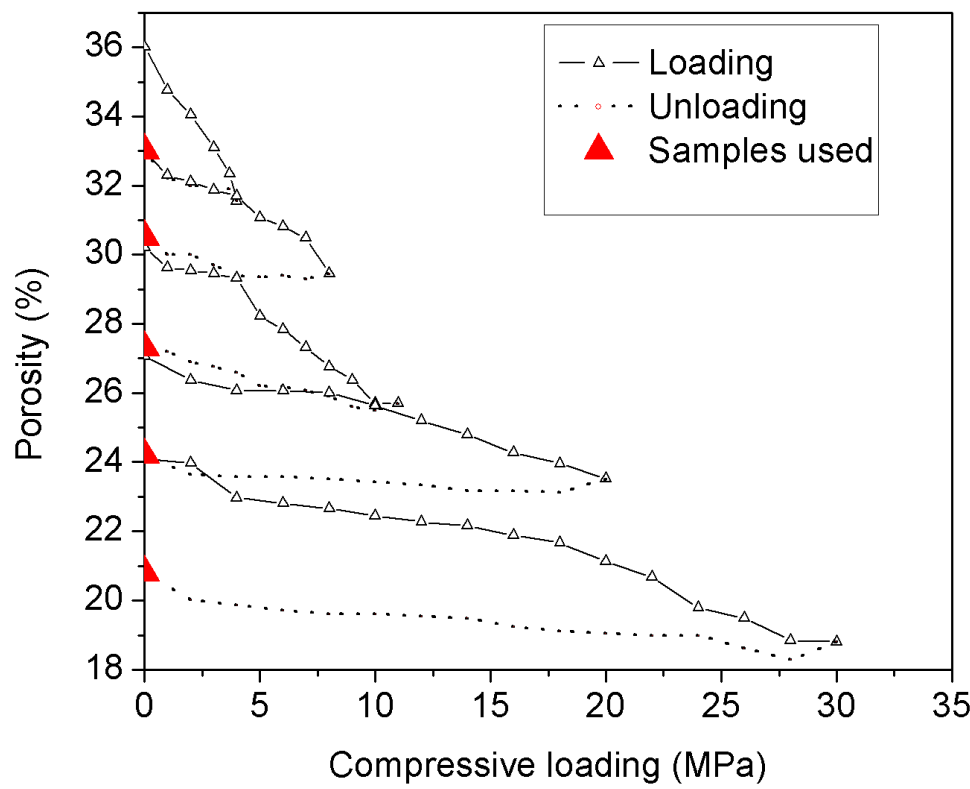

(b)

Figure 3. Sample molding machine and porous specimen (a) and loading process (b). 
repeatability of the samples (Figure $3(\mathrm{~b})$ ). The sample length was cut into 70 $\mathrm{mm}$ in length after compressed to make both end surfaces of the samples flat to contact the ultrasonic transducers. Porosity was controlled by the varied mass of the particles as well as the constant cross-sectional area, $\mathrm{S}, 40 \mathrm{~mm}$ in diameter and $70 \mathrm{~mm}$ in length. The parameter of the native sandstone is listed in Table 1.

After making the porous samples, a professional ultrasonic apparatus (Pundit lab+) were applied on these samples by using pulse transmission apparatus (Figure 4). A pair of transducers were inserted into the cells with two springs in case of the high pressure. During the measurement, an expected loading $(F c)$ which same as the one used in molding process was applied on the samples. The stress $(\sigma)$ applied on the samples could be obtained from

$$
\sigma=\frac{F c}{S}
$$

where $F_{\mathcal{C}}(\mathrm{MN})$ is compressive force, $\sigma(\mathrm{MPa})$ is the stress applied on the samples at each porosity by molding machine, and $S\left(\mathrm{~m}^{2}\right)$ is cross-sectional area of the sample.

The ultrasonic apparatus provided a wide range of ultrasonic frequencies from 24 to $500 \mathrm{kHz}$. The diameter of the transducers is $40 \mathrm{~mm}$ that was equal to the

Table 1. Physical parameters of sandstone used for present measurements.

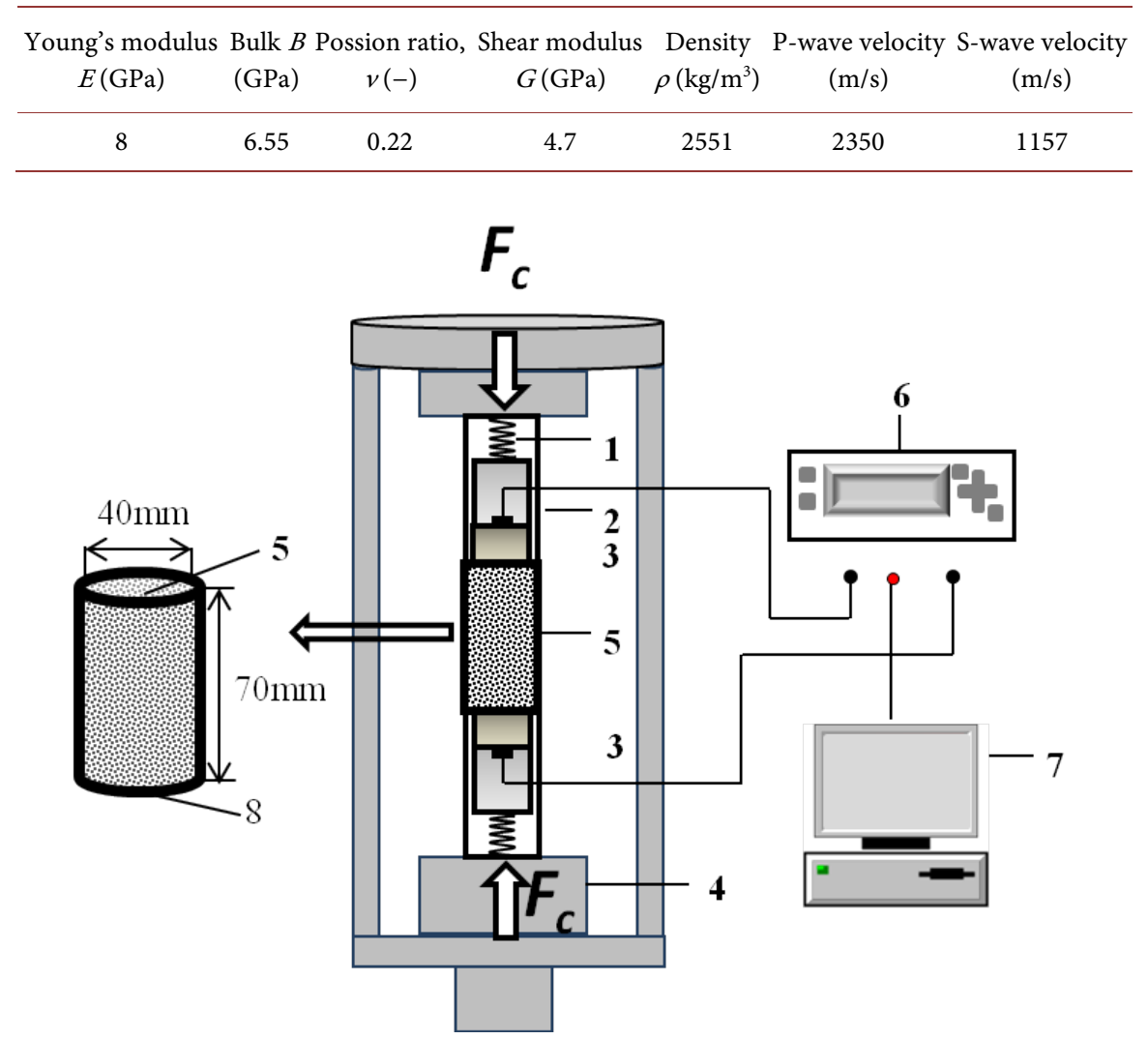

Figure 4. Measurement apparatus of seismic attenuation (1. spring; 2. piston; 3. transducers; 4. pedestal; 5. compressed porous sample; 6. pulse transmission apparatus and analyzer (Pundit Lab+); 7. storage and software; 8. PVC pipe, $S=1.26 \times 10^{-3} \mathrm{~m}^{2}$ ). 
diameter of the compressed sample. Velocity can be displayed directly on the screen of Pundit system based on the length of samples input into the system. The wave attenuation, $\beta(1 / \mathrm{m})$, is defined as

$$
\beta=-\frac{1}{x_{1}-x_{0}} \ln \left(\frac{A_{1}}{A_{0}}\right)
$$

where $f(\mathrm{~Hz})$ is the frequency; $A_{0}$ is the spectral amplitude of the incident wave; $A_{1}$ is the spectral amplitude of the transmitted wave; and $x_{1}-x_{0}(\mathrm{~m})$ is the propagation length.

\subsection{Permeability Measurement}

Permeability was measured by steady-state method using the following apparatus (Figure 5). Particles of sandstone were compressed into a PVC cup with a small hole in the bottom as the samples for measurement. The porosity and compressing loading of the specimen were kept the same as the samples used for ultrasonic measurement.

The permeability was calculated based on the Darcy's law,

$$
k=-\frac{Q \mu L}{S\left(P_{b}-P_{a}\right)}
$$

$Q\left(\mathrm{~m}^{3} / \mathrm{s}\right)$ is flow rate; $k\left(\mathrm{~m}^{2}\right)$ is coefficient of permeability; $S\left(\mathrm{~m}^{2}\right)$ is cross-sectional area of sample; $P_{b}-P_{a}(\mathrm{~Pa})$ is the pressure drop; $\mu(\mathrm{Pa})$ is viscosity of gas; $L(\mathrm{~m})$ is the length of sample.

\section{Results and Discussions}

After the text edit has been completed, the paper is ready for the template.

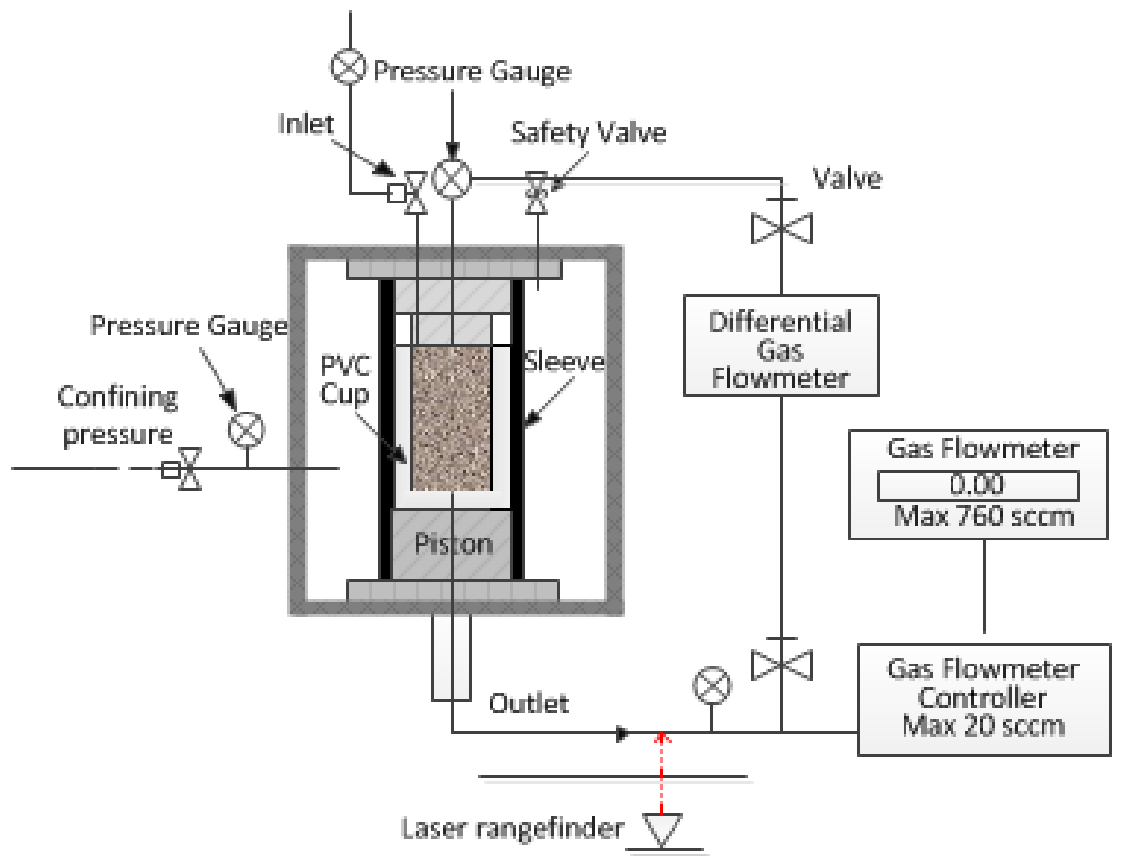

Figure 5. Schematic apparatus of permeability measurement. 
Duplicate the template file by using the Save As command, and use the naming convention prescribed by your journal for the name of your paper. In this newly created file, highlight all of the contents and import your prepared text file. You are now ready to style your paper.

\subsection{Seismic Velocity/Attenuation and Porosity}

Seismic velocity and attenuation of the samples in different porosity and particle sizes were measured under three frequencies, 37,54 and $82 \mathrm{kHz}$. It can be seen in Figure 6 that the velocity increased as the porosity reduced regardless of the particle size and frequency used. Compared to the previous empirical results presented [15] by measuring the native samples, our results showed less velocity at the same porosity. This means the cementation in the fractured space and welded surface in the native rock increase the integrity of the native samples and smooth of the wave propagation. Furthermore, the velocity obviously rose up with the increasing particle size at the same porosity. The frequency change showed less influence on the attenuation of the smaller particles. This is because the wavelength is much larger than the particle size in the smaller particle samples resulting in the less effect of the frequency on the attenuation.

As is shown in Figure 7 that attenuation noticeably reduced with the increasing porosity, especially for the smaller particle size. The slop of the attenuation versus porosity curve for the smaller particles showed larger than that of the larger particles. This illustrated the attenuation in the smaller particles is more susceptible to the porosity change. While, the attenuation for three particle sizes remained similar level when the porosity dropped to $24 \%$. It means the attenuation is more sensitive to the variation of the particle size within high porosity range. Basically, the attenuation decreased with the increasing particle size at a same porosity and frequency. Compared to the velocity change under different frequency, the attenuation is more likely to be effected by the variation of frequency.

\subsection{Permeability and Porosity}

Permeability of the samples was highly dependent on the porosity shown in Figure 8. Meanwhile, the permeability performed larger as the particle size increased. This is because the reduction of the particle size increase the tortuosity of the flowing path. Furthermore, along with the decrease of porosity, permeability of the different particle size tend to be close, which illustrated the effect of the particle size on the permeability decrease as the porosity reduces.

\section{Conclusions}

Sandstone particles were sieved into different sizes to make the porous samples in different porosities to study the correlations between the porosity and seismic characteristic as well as the permeability. The main results are summarized as follows. 


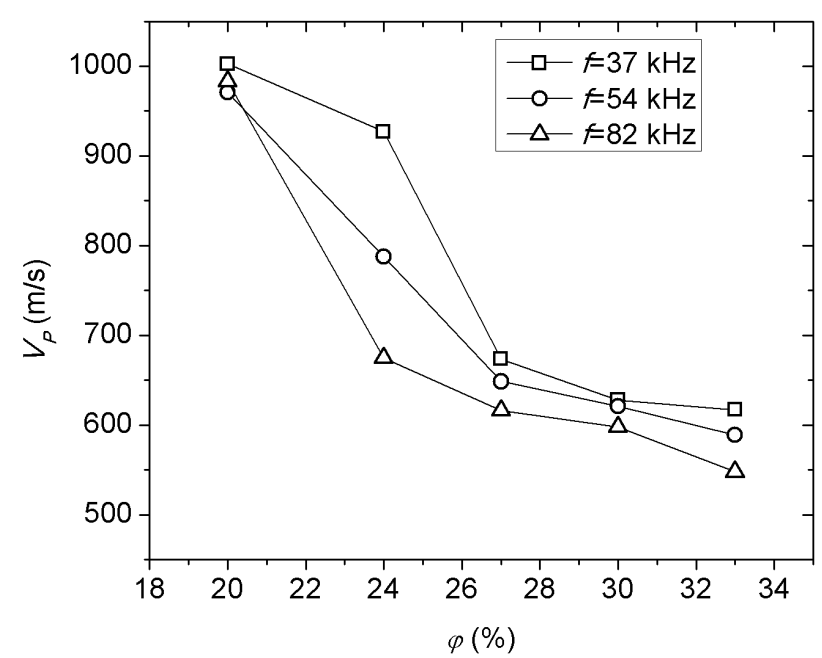

(a)

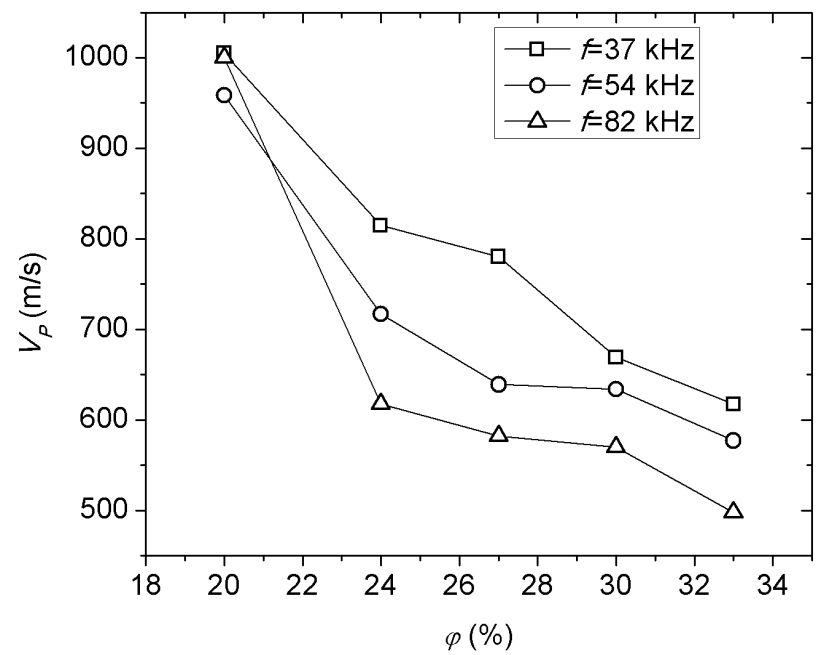

(b)

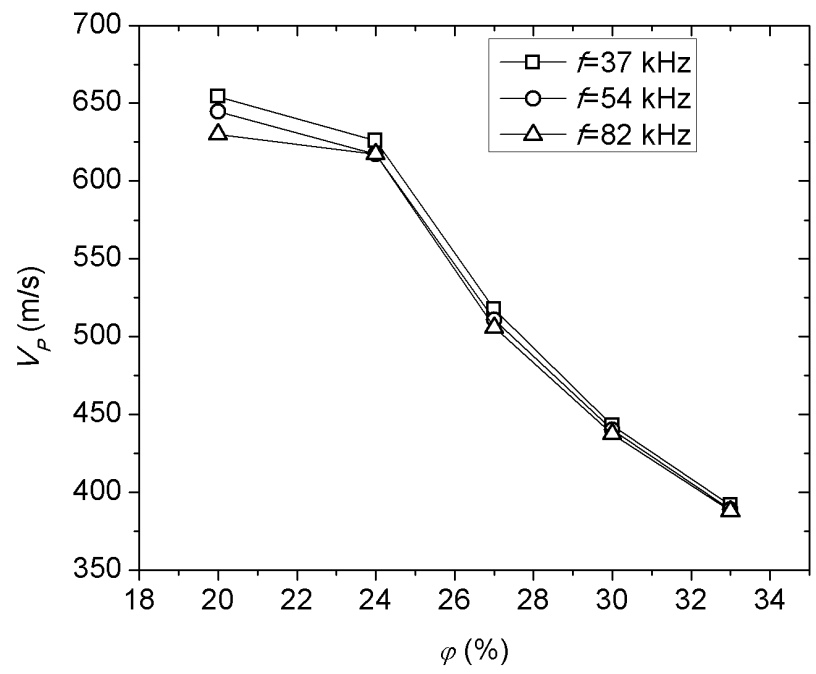

(c)

Figure 6. Seismic velocity versus porosity for different particle size.(a) $0.5-1.0 \mathrm{~mm}$ in diameter (b) $0.25-0.5 \mathrm{~mm}$ in diameter (c) $0.12-0.25 \mathrm{~mm}$ in diameter. 


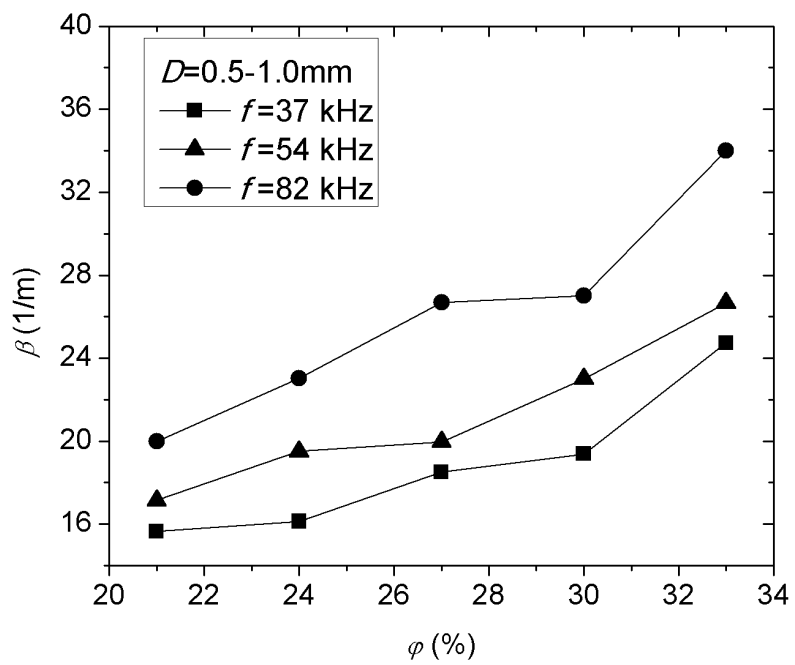

(a)

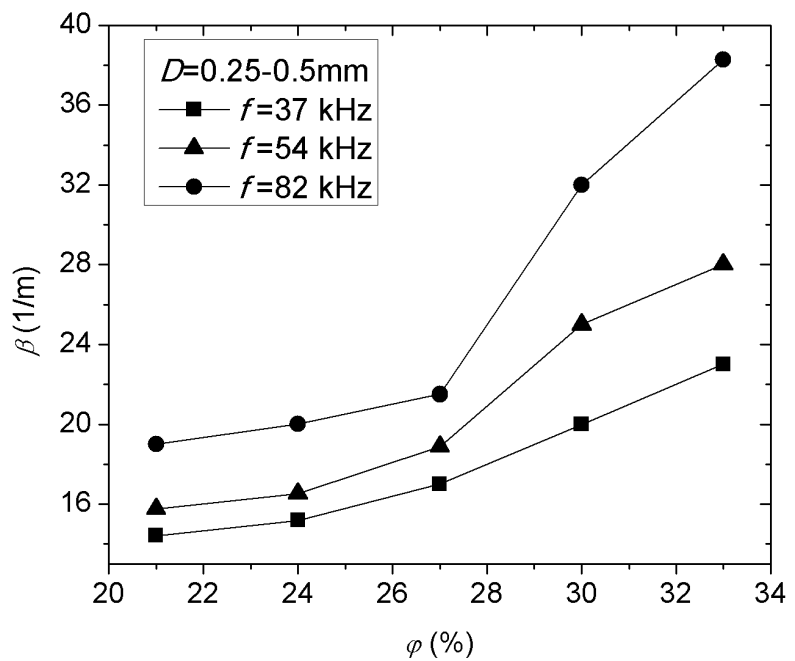

(b)

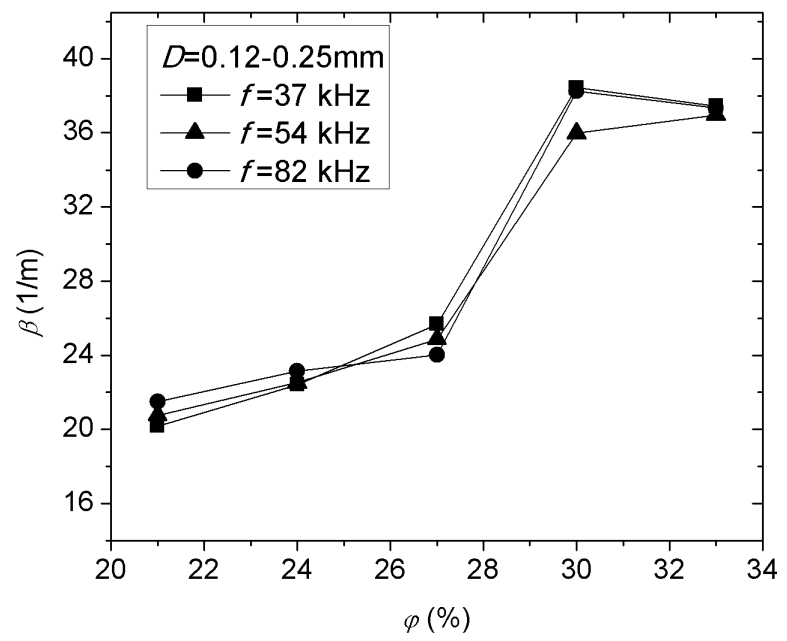

(c)

Figure 7. Seismic attenuation versus porosity for different particle sizes.(a) $0.5-1.0 \mathrm{~mm}$ in diameter (b) $0.25-0.5 \mathrm{~mm}$ in diameter (c) $0.12-0.25 \mathrm{~mm}$ in diameter. 


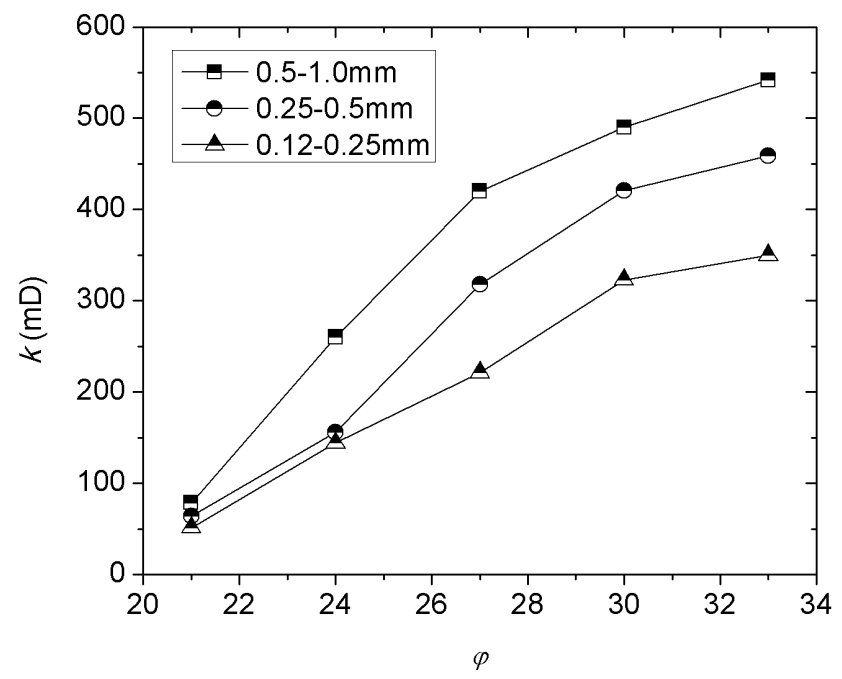

Figure 8. Permeability against porosity for different particle size.

1) Seismic wave propagating through the larger particle samples showed smaller attenuation compared to the smaller particle ones at the same porosity and frequency. Attenuation showed less dependent of particle size at porosity under $24 \%$.

2) The seismic attenuation of the porous samples showed less dependent on the frequency when wavelength is more than 170 times the particle size regardless of the porosity.

3) Permeability of the porous sample is less dependent on the particle size at porosity under $21 \%$.

\section{References}

[1] United States Congress Office of Technology Assessment (1981) An Assessment of Development and Production Potential of Federal Coal Leases. Congress of the U.S., Office of Technology Assessment, Washington DC.

[2] EIA, US (2011) International Energy Statistics. https://www.eia.gov/cfapps/ipdbproject/IEDIndex3.cfm?tid=1

[3] Yasitli, B. (2005) 3-D Numerical Modelling of Stresses around a Longwall Panel with Top Coal Caving. Journal of the Southern African Institute of Mining and Metallurgy, 105, 287-300. https://doi.org/10.1016/j.ijrmms.2004.08.007

[4] Karacan, C.Ö. (2010) Prediction of Porosity and Permeability of Caved Zone in Longwall Gobs. Transport in Porous Media, 82, 413-439. https://doi.org/10.1007/s11242-009-9437-7

[5] Gray, I. (1987) Reservoir Engineering in Coal Seams: Part 1-The Physical Process of Gas Storage and Movement in Coal Seams. SPE Reservoir Engineering, 2, 28-34. https://doi.org/10.2118/12514-pa

[6] Bear, J. (2013) Dynamics of Fluids in Porous Media. Courier Corporation, Chelmsford. https://doi.org/10.1097/00010694-197508000-00022

[7] Gochioco, L.M. (2000) High-Resolution 3-D Seismic Survey over a Coal Mine Reserve Area in the US-A Case Study. Geophysics, 65, 712-718.

https://doi.org/10.1190/1.1444770 
[8] Chen, T., Wang, X. and Mukerji, T. (2015) In Situ Identification of High Vertical Stress Areas in an Underground Coal Mine Panel Using Seismic Refraction Tomography. International Journal of Coal Geology, 149, 55-66. https://doi.org/10.1016/j.coal.2015.07.007

[9] Cao, A., Dou, L., Cai, W., Gong, S., Liu, S. and Jing, G. (2015) Case Study of Seismic Hazard Assessment in Underground Coal Mining Using Passive Tomography. International Journal of Rock Mechanics and Mining Sciences, 78, 1-9. https://doi.org/10.1016/j.ijrmms.2015.05.001

[10] Si, G., Durucan, S., Jamnikar, S., Lazar, J., Abraham, K., Korre, A., Shi, J.-Q., Zavšek, S., Mutke, G. and Lurka, A. (2015) Seismic Monitoring and Analysis of Excessive Gas Emissions in Heterogeneous Coal Seams. International Journal of Coal Geology, 149, 41-54. https://doi.org/10.1016/j.coal.2015.06.016

[11] Ge, M., Wang, H., Hardy, H. and Ramani, R. (2008) Void Detection at an Anthracite Mine Using an In-Seam Seismic Method. International Journal of Coal Geology, 73, 201-212. https://doi.org/10.1016/j.coal.2007.05.004

[12] Fimagalli, E. (1969) Test on Cohesionless Material for Rockfill Dams. Journal of the Soil Mechanics and Foundations Division, 95, 313-330.

[13] Hardin, B.O. (1985) Crushing of Soil Particles. Journal of Geotechnical Engineering, 111, 1177-1192. https://doi.org/10.1061/(asce)0733-9410(1985)111:10(1177)

[14] Palchik, V. (2002) Influence of Physical Characteristics of Weak Rock Mass on Height of Caved Zone over Abandoned Subsurface Coal Mines. Environmental Geology, 42, 92-101. https://doi.org/10.1007/s00254-002-0542-y

[15] Raymer, L., Hunt, E. and Gardner, J.S. (1980) An Improved Sonic Transit Time-to-Porosity Transform. Proceedings of Society of Petrophysicists and Well-Log Analysts, Houston, 1-13. 